\title{
Speeding up HCl Extractions by Employing Ultrasound Energy to Evaluate Trace Elements Bioavailability in Sediments
}

\author{
Vanessa Hatje, ${ }^{*, a}$ Letícia M. Costa, ${ }^{b}$ Maria Graças A. Korn ${ }^{a}$ and Gabriel Cotrim ${ }^{a}$ \\ ${ }^{a}$ Departamento de Química Analítica, Universidade Federal da Bahia, Campus de Ondina, \\ 40170-290 Salvador-BA, Brazil
}

${ }^{b}$ Departamento de Química, Instituto de Ciências Exatas, Universidade Federal de Minas Gerais, 31270-901 Belo Horizonte-MG, Brazil

\begin{abstract}
Uma análise de variância de três fatores foi usada para testar a significância do tipo de recipiente, tipo de material e número de replicatas na preparação de amostras de sedimento utilizando um banho ultra-sônico. A extração convencional com $\mathrm{HCl}$ 1,0 $\mathrm{mol} \mathrm{L}^{-1}$, por $0,5,4 \mathrm{e} 12 \mathrm{~h}$, foi modificada, e o banho ultra-sônico foi aplicado para diminuir o tempo de preparo de amostras. Os metais traço foram medidos por ICP OES. Os melhores resultados foram obtidos com frascos de Teflon ${ }^{\circledR}$ com base plana. Com exceção do $\mathrm{Ni}$, constatou-se que é possível trabalhar no banho de ultrasom em triplicatas, sem comprometer a eficiência e/ou precisão da extração. A eficiência de extração melhorou com o aumento no tempo de sonicação de 1 para $50 \mathrm{~min}$. Para a maioria dos elementos, a extração assistida por radiação ultra-sônica pode reduzir o tempo convencional de extração de $12 \mathrm{~h}$ para 50 min ou menos (i.e. 6 min para $\mathrm{Pb}$ ). A precisão obtida foi comparável aos valores obtidos com a extração convencional. O método proposto é rápido, barato e uma boa alternativa para o levantamento da biodisponibilidade e potencial de mobilidade de metais em sedimentos.
\end{abstract}

A three factors analysis of variance was used to test the significance of the type of vessel, the type of material and the number of replicates in the preparation of sediment samples using an ultrasonic bath. The conventional extraction with $\mathrm{HCl} 1.0 \mathrm{~mol} \mathrm{~L}^{-1}$, for $0.5,4$ and $12 \mathrm{~h}$, has been modified, applying an ultrasonic bath, in order to speeding up the sample preparation time. Trace metals were measured by an ICP OES. The best results were obtained using a Teflon ${ }^{\circledR}$ vessel with a flat bottom. For all metals but $\mathrm{Ni}$ it was demonstrated the feasibility of working in triplicates in the ultrasonic bath, without compromising the efficiency and/or the precision of the extraction. Leaching efficiency enhanced with increasing sonication time from 1 to $50 \mathrm{~min}$. For most elements the ultrasound-assisted leaching could reduce the conventional extraction time from $12 \mathrm{~h}$ to $50 \mathrm{~min}$ or even less (i.e. $6 \mathrm{~min}$ for $\mathrm{Pb}$ ). The precision obtained was comparable to values obtained for the conventional acid extraction. The proposed method is a fast, inexpensive and easy alternative for screening of the potential mobility and bioavailability of metals in sediments.

Keywords: ultrasonic bath, sample preparation, bioavailable metals, sediment

\section{Introduction}

Trace metals in sediments may exist in various chemical forms due to the nature of source, formation process, transport and depositional environment. For pristine sediments, trace metals are mainly associated with silicates, forming relatively insoluble species. Trace metals in polluted sediments are generally associated to more mobile phases (e.g. oxides of Fe and Mn, organic matter and carbonates). The latter is, often, considered to

*e-mail: vhatje@ufba.br be of environmental risk, because its potential availability and mobility which is related to sediments-biota transfer of pollutants. Therefore, considerable interest has been expressed in the determination of both total and bioavailable trace metals in sediment samples.

The dissolution of sediment samples is usually necessary for the determination of trace metals using common techniques such as flame and graphite furnace atomic absorption spectroscopy (F AAS, GF AAS), inductively coupled plasma optical emission and mass spectrometry (ICP OES, ICP-MS). The digestion usually requires acid leaching with concentrated mineral acids, i.e. 
$\mathrm{HNO}_{3}$ and aqua regia, with high temperatures and pressure. The wet digestion methods without using HF do not attack the silicate matrix, hence are not considered total digestion. However, for environmental studies, weak leached, such as diluted hydrochloric acid $(\mathrm{HCl})$, is commonly employed to obtain the available and potentially more toxic fraction of metals. The use of $\mathrm{HCl} 1.0 \mathrm{~mol} \mathrm{~L}^{-1}$ has been recommended, in sediment quality guidelines, for the assessment of regional contamination. ${ }^{1}$

Hydrochloric acid has been used to estimate the labile phases of trace metals in marine and estuarine sediments. Its reducing properties attack Fe and Mn oxides, which are a major sink for trace metals in oxic sediments. ${ }^{2,3}$ It is also efficient at decomposing organic phases and amorphous sulphides that control metal bioavailability in sub-oxic sediments. ${ }^{4}$

The pre-treatment is usually the most time-consuming step of elemental analysis. Therefore, alternatives have been studied to simplifying and speeding up the conventional methods of sample preparation, for instance, hot plate, microwave and overnight shaking. A number of authors have achieved good results using ultrasound probes and baths to reduce time in the pre-treatment of sediments. ${ }^{5-8}$

The ultrasound energy induces acoustic cavitation, which promotes a local high increase in temperature and pressure, alloying high analyte transport from solid particles, eroded and fragmented by the wave shock, to the liquid phase. ${ }^{9}$ The high temperature and pressure also lead to the formation of free radicals and other compounds..$^{10,11}$ Thus the pre-treatment is usually shortened compared to conventional methods without the utilization of extreme experimental conditions. The use of ultrasound energy in sample preparation has other advantages, for example does not require special vessels, the ultrasonic cleaning bath is inexpensive and widely available and there is no risk that extraction solution evaporates to dryness as in hot plate digestion. ${ }^{6}$

The aims of this study were: (i) to test the significance of the type of vessel (conical or flat), type of material (Teflon ${ }^{\circledR}$ or glass) and number of replicates, simultaneously prepared, in the ultrasonic bath using three factors analysis of variance; (ii) to speed up conventional extraction using $\mathrm{HCl} 1.0 \mathrm{~mol} \mathrm{~L}^{-1}$, largely used in the determination of bioavailable trace metals, by employing ultrasound bath. The tests were carried out using a sediment certified reference material.

\section{Experimental}

\section{Reagents, solutions and samples}

For ultrasonic extractions diluted $\mathrm{HCl} 1.0 \mathrm{~mol} \mathrm{~L}^{-1}$ was prepared from analytical reagent-grade concentrated $\mathrm{HCl}$
(37\% m/m, Merck, Darmstadt, Germany) and ultrapure water (Milli-Q ${ }^{\circledR}$, Millipore, USA) with resistivity higher than $18.2 \mathrm{M} \Omega \mathrm{cm}$, which was used throughout the work. The multielement reference solutions were prepared daily from $1000 \mathrm{mg} \mathrm{L}^{-1}$ stock solutions of each element (Titrisol ${ }^{\circledR}$, Merck, Germany). Calibration standards of each element were obtained by suitable dilution of the stock solutions. Laboratory glassware was kept overnight in $10 \% \mathrm{v} / \mathrm{v}$ nitric acid solution (Merck, Darmstadt, Germany). Before use the glassware was rinsed with ultrapure water and dried in a dust free environment.

An estuarine sediment Quality Control Material (QCM; SETS-1), collected at Todos os Santos Bay, Bahia, Brazil ${ }^{12}$ was used in the experiments to test the influence of the type of vessel and the number of replicates. Full description of SETS-1 is presented elsewhere. ${ }^{12}$ In order to test the efficiency of the ultrasound extractions, compared to the conventional procedure, the Certified Reference Marine Sediment, PACS-2 (NRC-CNR, Ontario, Canada) was used. The PACS-2 was collected in the harbour Esquimalt (BC) and presents moderately elevated concentrations of several elements (e.g. $\mathrm{Cu}, \mathrm{Mn}, \mathrm{Pb}$ and $\mathrm{Zn}$ ).

\section{Instrumentation}

An inductively coupled plasma optical emission spectrometer with axially-viewed configuration (ICP OES, VISTA PRO, Varian, Mulgrave, Australia) was used for trace elements determinations. The sample introduction system employed comprises a concentric nebulizer and a cyclonic spray chamber. The operational parameters employed are described in Table 1.

Table 1. Instrumental parameters for elements determinations using ICP OES with axially-viewed configuration

\begin{tabular}{|c|c|}
\hline \multicolumn{2}{|l|}{ Instrumental parameter } \\
\hline Generator frequency / MHz & 40 \\
\hline $\mathrm{RF}$ power / $\mathrm{kW}$ & 1.3 \\
\hline Plasma gas flow / $\left(\mathrm{L} \mathrm{min}^{-1}\right)$ & 15.0 \\
\hline Auxiliary gas flow / $\left(\mathrm{L} \mathrm{min}^{-1}\right)$ & 1.5 \\
\hline Nebuliser gas flow-rate / $\left(\mathrm{L} \mathrm{min}^{-1}\right)$ & 0.7 \\
\hline Sample flow-rate / $\left(\mathrm{mL} \mathrm{min}{ }^{-1}\right)$ & 0.8 \\
\hline Analytical wavelengths / nm & $\begin{array}{c}\text { Ba 455.403; Cu 228.615; } \\
\text { Co 228.615; Cr 267.716; } \\
\text { Fe 259.940; Ni 231.604; } \\
\text { Mn 257.610; Pb 220.353; } \\
\text { Zn 213.857 }\end{array}$ \\
\hline
\end{tabular}

An Ultrasonic Benchtop Cleaner WWR Model 75 D (Cortland, New York, USA), which produced a nominal frequency of $40 \mathrm{kHz}$ and power of $200 \mathrm{~W}$, equipped 
with a time counter, was used for sample preparation. A Centrifuge Model 5804 (Eppendorf, Germany), at 3000 rpm for $10 \mathrm{~min}$, was used to separate the final solution from the solid residue at the end of each extraction.

\section{Procedures}

Tests of the influence of type of vessel and number of replicates

A pilot study was performed in order to investigate the influence of type of material (Teflon ${ }^{\circledR}$ or glass), type of vessel bottom (conical or flat) and number of replicates (one or three treated simultaneously) in the efficiency of the extractions of trace elements. An aliquot of $250 \mathrm{mg}$ of SETS-1 was weighed directed in the reactor vessel and $15 \mathrm{~mL}$ of the solution was added. Ultrasonic extraction was performed for $30 \mathrm{~min}$, at a previous optimized position in the ultrasonic bath. ${ }^{11}$ A hierarchical sample design was applied, and the results were tested by a threefactor ANOVA. The first factor was the type of material (orthogonal, two levels), the second factor was the type of bottom (orthogonal, fixed with two levels) and the third factor was the number of replicates (orthogonal, fixed with two levels). Three replicates were used in this experiment. Homogeneity of variances was examined using Cochran's test. Multiple comparisons among means were performed with the Student-Newman-Keul's (SNK) test.

\section{Conventional acid extraction}

Approximately $250 \mathrm{mg}$ of dried sample was placed into a clean $50 \mathrm{~mL}$ Teflon ${ }^{\circledR}$ vessel and $15 \mathrm{~mL}$ of $1.0 \mathrm{~mol} \mathrm{~L}^{-1}$ $\mathrm{HCl}$ were added. Extractions were conducted on an orbital shaker and the supernatants were separated immediately by centrifugation at $3000 \mathrm{rpm}$ for $10 \mathrm{~min}$. The extractions were realized for $0.5,4$ and $12 \mathrm{~h}$ at room temperature. The final solutions were collected in polyethylene flasks for element determinations. Blanks were treated in the same experimental conditions.

\section{Ultrasound assisted extraction}

For ultrasonic assisted extraction the importance of the duration of the sonication process was evaluated. The time range between 1 and $50 \mathrm{~min}$ was studied (i.e. sonication for $1,2,4,6,12,25$, and $50 \mathrm{~min})$. To evaluate the efficiency of this process, the results obtained by the ultrasonic assisted extraction were compared with those from the conventional extraction.

A mass of approximately $250 \mathrm{mg}$ of dried sample was weighed into Teflon ${ }^{\circledR}$ flasks and $15 \mathrm{~mL}$ of $1.0 \mathrm{~mol} \mathrm{~L}^{-1} \mathrm{HCl}$ was added. Then, the sample was sonicated for periods of time varying from 1 to $50 \mathrm{~min}$. After sonication, the solution was centrifuged, and the supernatant separated for element determinations by ICP OES. All experiments were performed in triplicate and blanks were also treated as sediment samples.

\section{Results and Discussion}

\section{Tests of the influence of type of vessel and number of replicates}

The results of these tests are presented in Table 2. The data showed that the material of the vessel employed for extractions was significant for $\mathrm{Co}, \mathrm{Cr}, \mathrm{Ni}$ and $\mathrm{Mn}$. For all metals that the material had a significant influence in the extraction efficiency, the best results were obtained with Teflon ${ }^{\circledR}$. The type of the bottom of vessel was also significant for $\mathrm{Mn}, \mathrm{Ni}, \mathrm{Zn}$ and $\mathrm{Cu}$. The best results were obtained with flat bottom, the only exception was Ni. Based on these results, the optimization of the extraction was performed using a Teflon ${ }^{\circledR}$ vessel with a flat bottom.

It is well know that several vessels in the ultrasonic bath can cause wave reflection and thus reduction in the sonication processes. ${ }^{13}$ Nevertheless, only the extractions of $\mathrm{Ni}$ were significantly affected by the number of replicates prepared simultaneously at the ultrasonic bath. Hence, it shows the feasibility to work in triplicates in the ultrasonic bath without compromising the efficiency and/ or the precision of the extraction. It should be noted that it is recommended to use always the same positions in the ultrasonic bath.

\section{Conventional acid extraction}

A number of different extraction times have been proposed for $\mathrm{HCl}$ extractions, varying from 0.5 to $24 \mathrm{~h} .{ }^{1,14}$ Prior to the systematic investigation of ultrasonic extraction procedures, the conventional orbital agitation ${ }^{15,16}$ was applied to the PACS-2 certified reference sediment. The concentrations obtained for extraction times of $0.5,4$ and $12 \mathrm{~h}$, after repeated experiments, carried out by different analysts, are presented in Table 3. The recovery percentages for $\mathrm{HCl}$ extractions varied from $8.11 \%(\mathrm{Mn})$ to $73.4 \%$ ( $\mathrm{Pb}$ and $\mathrm{Zn}$ ). The low percentages of recovery are expected, since a diluted, cold solution was employed. There are no certified values for $\mathrm{HCl}$ extractions, although its worldwide use to evaluate bioavailable metals in sediments. Nevertheless, most of the results agreed well with data reported by Townsend et al. ${ }^{15}$ which also used $4 \mathrm{~h} \mathrm{HCl} 1.0 \mathrm{~mol} \mathrm{~L}^{-1}$ extraction for PACS-2 sediment.

The extractability power of $\mathrm{HCl}$ is clearly dependent on the time of exposure of sediments (Figure 1). Nevertheless, 
Table 2. Sumary of three-factor ANOVA of trace element concentrations in SETS-1 sediment sample

\begin{tabular}{|c|c|c|c|c|c|c|c|c|c|c|c|c|c|}
\hline \multirow[b]{2}{*}{ Source of Variation } & \multirow[b]{2}{*}{ d.f. } & \multicolumn{3}{|c|}{$\mathrm{Mn}$} & \multicolumn{3}{|c|}{$\mathrm{Cu}$} & \multicolumn{3}{|c|}{$\mathrm{Ni}$} & \multicolumn{3}{|c|}{$\mathrm{Zn}$} \\
\hline & & MS & $\mathrm{F}$ & $\mathrm{P}$ & MS & $\mathrm{F}$ & $\mathrm{P}$ & MS & $\mathrm{F}$ & $\mathrm{P}$ & MS & $\mathrm{F}$ & $\mathrm{P}$ \\
\hline Material (Ma) & 1 & 1212 & 35.4 & $* * *$ & 0.0513 & 0.38 & ns & 1.955 & 7.39 & $*$ & 119.2 & 2.58 & $\mathrm{~ns}$ \\
\hline Bottom (Bo) & 1 & 290.4 & 8.48 & $*$ & 4.797 & 35.7 & $* * *$ & 2.740 & 10.4 & $*$ & 216.1 & 4.67 & $*$ \\
\hline Number of Replicates (Re) & 1 & 16.29 & 0.48 & ns & 0.1552 & 1.15 & ns & 1.680 & 6.35 & $*$ & 115.5 & 2.50 & $\mathrm{~ns}$ \\
\hline Ma x Bo & 1 & 78.45 & 2.29 & ns & 1.777 & 13.2 & $*$ & 7.627 & 28.8 & $* * *$ & 493.6 & 10.7 & $*$ \\
\hline Ma x Re & 1 & 285.6 & 8.34 & $*$ & 0.6501 & 4.83 & $*$ & 1.097 & 4.15 & ns & 143.7 & 3.10 & ns \\
\hline Bo $x \operatorname{Re}$ & 1 & 0.0234 & 0.00 & ns & 0.0051 & 0.04 & ns & 1.368 & 5.17 & $*$ & 109.5 & 2.37 & ns \\
\hline Ma x Bo x Re & 1 & 67.91 & 1.98 & ns & 0.2109 & 1.57 & $\mathrm{~ns}$ & 0.5370 & 2.03 & $\mathrm{~ns}$ & 79.5 & 1.72 & ns \\
\hline \multirow[t]{2}{*}{ Residual } & 16 & 34.26 & & & 0.1345 & & & 0.2645 & & & 46.3 & & \\
\hline & & \multicolumn{3}{|c|}{$\mathrm{Cr}$} & \multicolumn{3}{|c|}{ Co } & \multicolumn{3}{|c|}{$\mathrm{Pb}$} & & & \\
\hline Source of Variation & d.f. & MS & $\mathrm{F}$ & $\mathrm{P}$ & MS & $\mathrm{F}$ & $\mathrm{P}$ & MS & $\mathrm{F}$ & $\mathrm{P}$ & & & \\
\hline Material (Ma) & 1 & 122.7 & 74.1 & $* * *$ & 0.9087 & 15.4 & $*$ & 1.520 & 2.63 & $\mathrm{~ns}$ & & & \\
\hline Bottom (Bo) & 1 & 0.0368 & 0.02 & ns & 0.1926 & 3.27 & ns & 0.8513 & 1.47 & $\mathrm{~ns}$ & & & \\
\hline Number of Replicates (Re) & 1 & 0.5281 & 0.32 & ns & 0.1162 & 1.97 & ns & 0.0096 & 0.02 & ns & & & \\
\hline Ma x Bo & 1 & 7.820 & 4.72 & $*$ & 0.0828 & 1.41 & ns & 0.4593 & 0.80 & ns & & & \\
\hline Ma x Re & 1 & 0.0043 & 0.00 & ns & 0.0117 & 0.20 & $\mathrm{~ns}$ & 0.1536 & 0.27 & ns & & & \\
\hline Bo $x \mathrm{Re}$ & 1 & 0.7776 & 0.47 & ns & 0.0759 & 1.29 & ns & 0.8664 & 1.50 & ns & & & \\
\hline Ma x Bo x Re & 1 & 0.0963 & 0.06 & ns & 0.0715 & 1.21 & ns & 1.109 & 1.92 & ns & & & \\
\hline Residual & 16 & 1.655 & & & 0.0589 & & & 0.5773 & & & & & \\
\hline
\end{tabular}

d.f. $=$ degree of freedom, $\mathrm{MS}=$ mean square, $\mathrm{F}=\mathrm{F}$-ratio test, $\mathrm{n}=3, \mathrm{~ns}=$ no significant differences, *significance at $\mathrm{P} \leq 0.05$ and $* * *$ significance at $\mathrm{P} \leq 0.001$.

Table 3. Concentrations of trace and major elements in PACS-2 $(n=5)$ obtained using $1.0 \mathrm{~mol} \mathrm{~L}^{-1} \mathrm{HCl}$ using conventional shaking

\begin{tabular}{|c|c|c|c|c|c|c|c|}
\hline & \multicolumn{2}{|c|}{$0.5 \mathrm{~h}$} & \multicolumn{2}{|c|}{$4 \mathrm{~h}$} & \multicolumn{2}{|c|}{$12 \mathrm{~h}$} & \multirow[b]{2}{*}{$\begin{array}{l}\text { Certified } \\
\left(\mathrm{mg} \mathrm{kg}^{-1}\right)\end{array}$} \\
\hline & $\begin{array}{l}\text { Obtained } \\
\left(\mathrm{mg} \mathrm{kg}^{-1}\right)\end{array}$ & $\begin{array}{c}\text { Recovery }{ }^{\mathrm{a}} \\
(\%)\end{array}$ & $\begin{array}{l}\text { Obtained } \\
\left(\mathrm{mg} \mathrm{kg}^{-1}\right)\end{array}$ & $\begin{array}{c}\text { Recovery } \\
(\%)\end{array}$ & $\begin{array}{l}\text { Obtained } \\
\left(\mathrm{mg} \mathrm{kg}^{-1}\right)\end{array}$ & $\begin{array}{c}\text { Recovery }{ }^{a} \\
(\%)\end{array}$ & \\
\hline $\mathrm{Ba}$ & $95.3 \pm 1.9$ & - & $174 \pm 5$ & - & $221 \pm 3$ & - & - \\
\hline Co & $1.73 \pm 0.1$ & 15.0 & $2.85 \pm 0.2$ & 24.8 & $3.85 \pm 0.3$ & 33.5 & $11.5 \pm 0.3$ \\
\hline $\mathrm{Cr}$ & $7.75 \pm 0.1$ & 8.54 & $12.0 \pm 0.4$ & 13.2 & $15.6 \pm 0.5$ & 17.2 & $90.7 \pm 4.6$ \\
\hline $\mathrm{Cu}$ & $124 \pm 1$ & 40.0 & $162 \pm 8$ & 52.3 & $174 \pm 7$ & 56.1 & $310 \pm 12$ \\
\hline $\mathrm{Fe}$ & $6218 \pm 196$ & 15.2 & $7757 \pm 98$ & 19.0 & $9183 \pm 58$ & 22.5 & $40900 \pm 600$ \\
\hline $\mathrm{Mn}$ & $35.7 \pm 3.1$ & 8.11 & $57.6 \pm 3.6$ & 13.1 & $83.7 \pm 1.8$ & 19.0 & $440 \pm 19$ \\
\hline $\mathrm{Ni}$ & $5.05 \pm 0.2$ & 12.8 & $7.90 \pm 0.2$ & 20.0 & $11.0 \pm 0.3$ & 27.8 & $39.5 \pm 2.3$ \\
\hline $\mathrm{Pb}$ & $123 \pm 3$ & 67.2 & $130 \pm 3$ & 71.0 & $135 \pm 5$ & 73.4 & $183 \pm 8$ \\
\hline $\mathrm{Zn}$ & $222 \pm 7$ & 60.1 & $254 \pm 6$ & 69.8 & $267 \pm 6$ & 73.4 & $364 \pm 23$ \\
\hline
\end{tabular}

apercentage of certified reference values.

metals reacted differently. Lead, $\mathrm{Cu}$ and $\mathrm{Zn}$ were rapidly extracted from sediments, a recovery between 40 and $67 \%$ could be achieved when $0.5 \mathrm{~h}$ procedure was applied, indicating a fast kinetic extraction of these labile metals. This extraction behavior seems to be controlled by the source of metals, whether it is natural or anthropogenic. ${ }^{16}$ That is because anthropogenic metals are more likely to be weakly bound to the mineral matrix than elements from lithogenic sources. Slow kinetics reflects extraction of less mobile, inert phases typical of naturally occurring metals in the sediment matrix.

\section{Ultrasound assisted extraction}

The detection limits for trace elements obtained after ultrasound assisted extraction were 0.7, 1.0, 2.7, 3.8, 7.4, 

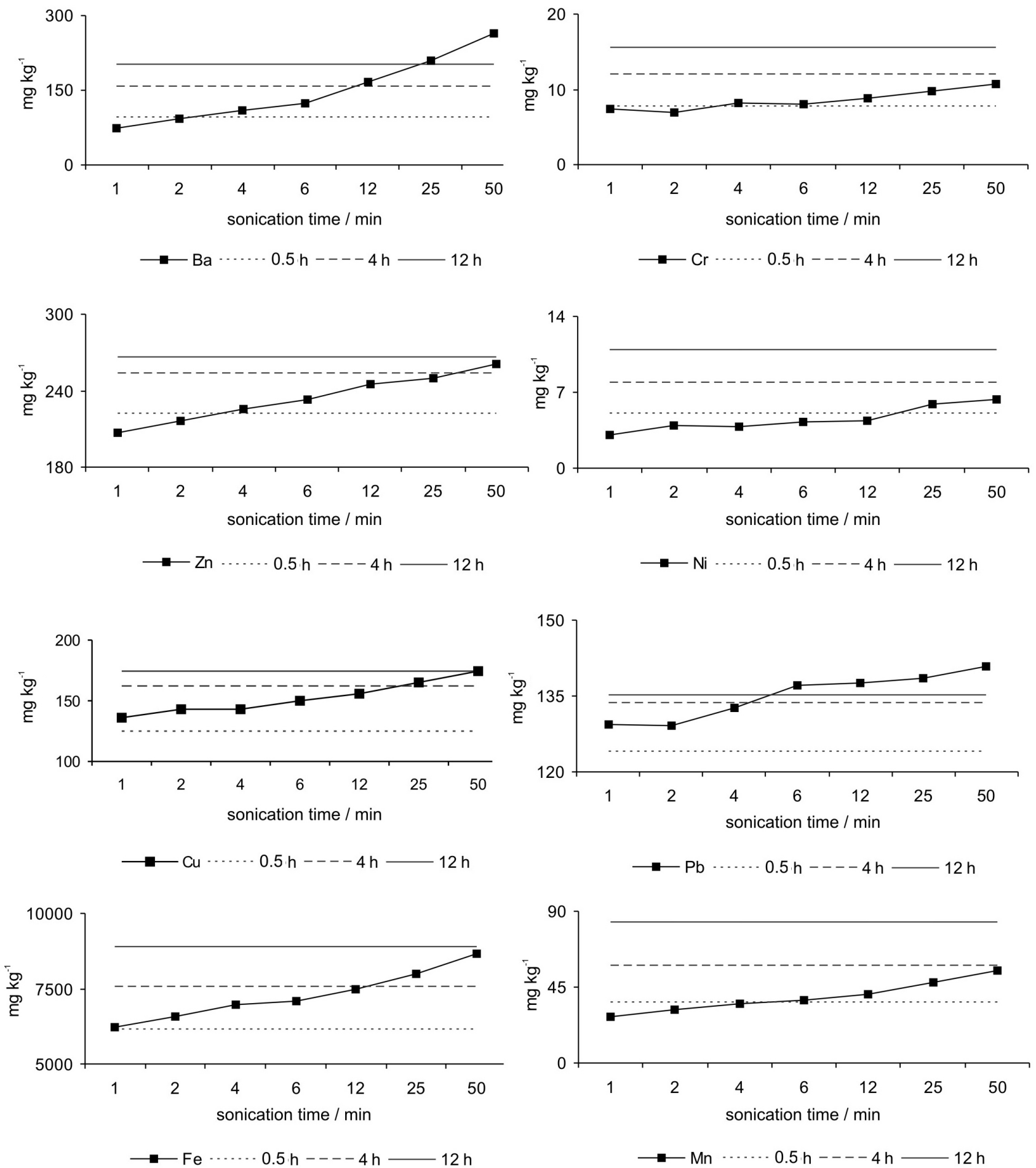

Figure 1. Comparison of trace and major elements extractability from PACS-2 by conventional leaching for $0.5,4$ and $12 \mathrm{~h}$ and ultrasound assisted extraction (line with black squares).

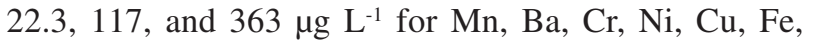
$\mathrm{Pb}$, and $\mathrm{Zn}$, respectively. The relative standard deviation $(\mathrm{RSD})(\mathrm{n}=3)$ values, for all metals, varied in the range of $0.6-19.4 \%$. For most elements the RSD values were below $3 \%$, and were comparable to values obtained for the conventional acid extraction. $\mathrm{Ni}$ and $\mathrm{Cr}$, the elements that presented the lowest concentration in the CRM, were the elements that presented the highest RSD values. Moreover, the highest RSD values were obtained when 1-6 min sonication time was employed.

Table 4 shows the results obtained for $\mathrm{HCl}$ extraction using ultrasound energy. For all metals the percentage 
Table 4. PACS -2 recovery percentages and standard deviation $(n=3)$ for ultrasound extractions as a function of sonication time

\begin{tabular}{lcccccccc}
\hline \multicolumn{7}{c}{ Sonication times } & PACS-2 \\
\cline { 2 - 6 } & $1 \mathrm{~min}$ & $2 \mathrm{~min}$ & $4 \mathrm{~min}$ & $6 \mathrm{~min}$ & $12 \mathrm{~min}$ & $25 \mathrm{~min}$ & $50 \mathrm{~min}$ & Certified values / $\left(\mathrm{mg} \mathrm{kg}{ }^{-1}\right)$ \\
\hline $\mathrm{Ba}$ & - & - & - & - & - & - & - & - \\
$\mathrm{Cr}$ & $8.19 \pm 0.9$ & $7.61 \pm 0.2$ & $9.01 \pm 0.8$ & $8.86 \pm 1.2$ & $9.68 \pm 0.7$ & $10.8 \pm 0.6$ & $12.0 \pm 1.4$ & $90.7 \pm 4.6$ \\
$\mathrm{Cu}$ & $43.9 \pm 0.8$ & $46.1 \pm 1.6$ & $46.1 \pm 1.1$ & $48.4 \pm 0.51$ & $50.3 \pm 2.5$ & $53.2 \pm 0.7$ & $56.1 \pm 1.4$ & $310 \pm 12$ \\
$\mathrm{Fe}$ & $15.3 \pm 0.1$ & $16.1 \pm 0.9$ & $17.1 \pm 0.3$ & $17.4 \pm 0.3$ & $18.3 \pm 0.5$ & $19.6 \pm 0.2$ & $21.2 \pm 0.5$ & $40900 \pm 600$ \\
$\mathrm{Mn}$ & $6.16 \pm 0.1$ & $7.14 \pm 0.8$ & $8.02 \pm 0.3$ & $8.39 \pm 0.2$ & $9.23 \pm 0.4$ & $10.8 \pm 0.3$ & $12.5 \pm 0.5$ & $440 \pm 19$ \\
$\mathrm{Ni}$ & $7.82 \pm 1.5$ & $10.1 \pm 0.5$ & $9.70 \pm 1.0$ & $10.7 \pm 1.0$ & $11.1 \pm 1.3$ & $11.1 \pm 1.3$ & $16.1 \pm 2.0$ & $39.5 \pm 2.3$ \\
$\mathrm{~Pb}$ & $70.5 \pm 0.8$ & $70.5 \pm 2.4$ & $72.7 \pm 3.2$ & $74.9 \pm 2.5$ & $75.4 \pm 1.4$ & $76.0 \pm 2.4$ & $77.1 \pm 0.8$ & $183 \pm 8$ \\
$\mathrm{Zn}$ & $56.9 \pm 1.5$ & $59.3 \pm 3.2$ & $61.8 \pm 1.4$ & $64.0 \pm 1.5$ & $67.3 \pm 1.4$ & $68.4 \pm 0.7$ & $71.7 \pm 1.1$ & $364 \pm 23$ \\
\hline
\end{tabular}

Result as percentage of certified value. There is no certified value for Ba.

extracted with ultrasound was below $100 \%$ (i.e. certified value concentration). Lead, $\mathrm{Zn}$ and $\mathrm{Cu}$ were the elements that presented the highest recoveries, which is possibly associated to their anthropogenic origin and, therefore, its labile nature.

Figure 1 shows a comparison between ultrasonicassisted leaching rate curves and the results obtained by conventional acid extraction at $0.5,4$ and $12 \mathrm{~h}$. For the studied elements, leaching efficiency increased with increasing sonication time from 1 to $50 \mathrm{~min}$. For most studied elements the ultrasound-assisted leaching could reduce the conventional extraction time from $12 \mathrm{~h}$ to $50 \mathrm{~min}$ (e.g. $\mathrm{Cu}, \mathrm{Fe}$ and $\mathrm{Zn}$ ) or even less for $\mathrm{Ba}(25 \mathrm{~min})$ and $\mathrm{Pb}$ (6 min), hence representing and important economy of sample preparation time. Extractions with $\mathrm{HCl}$ that employed $4 \mathrm{~h}$ exposure time could be performed in less than $50 \mathrm{~min}$ of sonication, while $12 \mathrm{~min}$ sonication time was necessary to reach the extraction efficiency obtained with 0.5 h conventional shaking. For the elements strongly associated to the silicated matrix (i.e. $\mathrm{Ni}$ and $\mathrm{Cr}$ ) the efficiency of sonication was reduced, compared to the more labile elements that presented high concentrations in the sediments.

\section{Conclusions}

Ultrasound energy represents a fast, reliable, and safe alternative to conventional acid extraction for the determination of bioavailable metals in sediments, when employing $\mathrm{HCl} 1.0 \mathrm{~mol} \mathrm{~L}^{-1}$. The conventional extraction time could be reduced from $12 \mathrm{~h}$ to $6 \min$ (i.e. $\mathrm{Pb}$ ), depending on the element of interest and the time used for the conventional extraction (e.g. 0.5, 1, 4, and 12 h). For most elements the precision obtained with ultrasound and conventional extraction was comparable. The study showed that Teflon ${ }^{\circledR}$ vessels with flat bottom should be employed, and triplicate samples could be treated simultaneously in the ultrasonic bath, without compromising the efficiency and/ or the precision of the extraction. The ultrasound assisted extraction employing $\mathrm{HCl} 1.0 \mathrm{~mol} \mathrm{~L}^{-1}$ is a fast, inexpensive, simple, and reproducible method for the estimation of the availability of trace metals

\section{Acknowledgments}

This work was funded by CNPq (478602/2006-5) and FAPESB. V. Hatje and M. G. A. Korn are grateful to Conselho Nacional de Desenvolvimento Científico e Tecnológico (CNPq) for the fellowships.

\section{References}

1. ANZECC; Australian and New Zealand Guidelines for Fresh and Marine Water Quality, Australian and New Zealand Environment and Conservation Council / Agriculture and Resource Management Council of Australia and Zew Zealand: Camberra, ACT, Australia, 2000.

2. Luoma, S. N.; Bryan, G. W.; Sci. Total Environ. 1981, 17, 165.

3. Kersten, M.; Forstner, U.; Geo-Mar. Lett. 1991, 11, 184.

4. Hall, G. E. M. In Manual of Physico-Chemical Analysis of Aquatic Sediments; Mudroch, A.; Azdue, J. M.; Mudroch, P., eds.; Lewis Publishers: Boca Raton, 1997.

5. Perez-Cid, B.; Lavilla, I; Bendicho, C.; Anal. Chim. Acta 1998, $360,35$.

6. Brunori, C.; Ipolyi, I.; Macaluso, L.; Anal. Chim. Acta 2004, 510, 101.

7. Canepari, S.; Cardarelli, E.; Ghighi, S.; Talanta 2005, 66, 1122.

8. Güngör, H.; Elik, A.; Microchem. J. 2007, 86, 65.

9. Capelo, J. L.; Galesio, M. M.; Felisberto, G. M.; Vaz, C.; Costa Pessoa, J.; Talanta 2005, 66, 1272. 
10. Carvalho, L. R. F.; Souza, S. R.; Martinis, S. B.; Korn, M.; Anal. Chim. Acta 1995, 317, 171.

11. Nascentes, C. C.; Korn, M.; Sousa, C. S.; Arruda, M. A. Z.; J. Braz. Chem. Soc. 2001, 12, 57.

12. Hatje, V.; dos Santos, D. S. S.; Korn, M. G. A.; J. Braz. Chem. Soc. 2006, 17, 357.

13. Priego-Capote, F.; Luque de Castro, M. D.; Methods 2007, 70, 299.
14. McCready, S.; Birch, G. F.; Taylor, S. E.; Aust. J. Earth Sci. 2003, 50, 249.

15. Townsend, A.T.; Palmer, A. S.; Stark, S. C.; Samson, C.; Scouller, R. C.; Snape, I.; Mar. Pollut. Bull. 2007, 54, 226.

16. Snape, I.; Scouller, R. C.; Stark, S. C.; Stark, J.; Riddle, M. J.; Gore, D. B.; Chemosphere 2004, 57, 491.

Received: August 7, 2008 Web Release Date: March 20, 2009 